\title{
Amerika Birleşik Devletleri'nin güney eyaletlerinde yapılan ağaçlandırmaların Türkiye açısından değerlendirilmesi
}

From the point of view for Turkey, assessment of planted forests in the southern states of the United States

Murat $\mathrm{ALAN}^{1}$

'Karabük Üniversitesi, Karabük

Sorumlu yazar (Corresponding author) Murat ALAN

muratalan@karabuk.edu.tr

Geliş tarihi (Received)

26.08.2020

Kabul Tarihi (Accepted)

24.09.2020

Sorumlu editör (Corresponding editor) Ercan VELİĞLU

ercanvelioglu@ogm.gov.tr

Atıf (To cite this article): Alan, M . (2021). Amerika Birleșik Devletleri'nin güney eyaletlerinde yapılan ağaçlandırmaların Türkiye açısından değerlendirilmesi . Ormancılık Araştırma Dergisi 8 (1) , 42-53 . DOI: $10.17568 /$ ogmoad. 785456

\section{$\ddot{O} z$}

Ağaçlandırmalar dünya ormanlık alanının \%7'sini oluşturmasına karșın, toplam odun hammaddesiüretiminin \%50'sini karșılamaktadır. Bu kapsamda, ABD'nin güney eyaletlerinde 1950'lerden bu yana çok başarılı ağaçlandırma çalışmaları yürütülmektedir. Bu çalışmalar için özel kuruluşlar, devlet orman işletmeleri ve üniversitenin bir araya geldiği bir kooperatif sistemi oluşturulmuştur. 1950'lerden bu yana ağaçlandırma alanları yaklaşık 15 kat, yıllık ortalama artım ise beş kat artırılmıştır. Ayrıca yıllık ortalama artımda sağlanan bu başarının bir sonucu olarak da idare süreleri 50 yıldan 18 yıla inmiştir. Türkiye'de de yarım yüzyılı aşkın bir süredir ağaçlandırma çalışmaları yürütülmektedir. Ayrıca ağaç ıslahında da Türkiye'de en büyük yayılış alanına sahip kızılçam için iyi bir alt yapı olduğu görülmektedir. Türkiye'deki ağaçlandırma çalışmalarının, devlet ve özel sektör tarafından geniş ölçüde benimsenmiş, ormancılık yönetiminin ayrılmaz bir parçası haline getirilmiş, sürdürülebilir bir yapı gösteremediği düşünülmektedir. Bu kapsamda $\mathrm{ABD}$ 'nin güney eyaletlerinde yapılan ağaçlandırma çalışmaları incelenmiş ve Türkiye için bir değerlendirme yapılarak öneriler getirilmiştir.

Anahtar kelimeler: Odun hammaddesi, ağaç ıslahı, silvikültür, tohum bahçesi

\begin{abstract}
Although planted forests constitute 7\% of the world's forest area, they contribute $50 \%$ of the total wood raw material production. In this context, very successful planted forests have been carried out in the southern states of the USA since the 1950s. For these studies, a cooperative system where private institutions, state forestry enterprises, and the university came together was established. Planted forest areas have been increased approximately 15 times, and the annual average increment has been increased five times since the 1950s. Besides, because of this success achieved in the annual average increase, rotation age decreased from 50 to 18 years. Turkey also has more than half a century, planted forests are carried out. Also, it is seen that a good tree improvement experience for that Turkish red pine has the largest distribution area in Turkey. Planted forests efforts in Turkey, that has been widely adopted by the state and the private sector and has become an integral part of forestry management is considered not to show a sustainable structure. In this context, the studies examined plantation in the southern states of the US and made an assessment for Turkey, proposals have been made.
\end{abstract}

Key words: Wood raw material, tree breeding, silviculture, seed orchard 


\section{Giriş}

Ağaçlandırmaların öne çıkan işlevlerinden birisi odun hammaddesi ihtiyacının sürdürülebilir bir şekilde karşılanmasıdır. Bu kapsamda, doğal ormanların üretim kapasitesinin toplumun odun hammaddesi gereksinimlerini karşılamada yetersiz kalması üzerine, odun üretimi amaçlı ağaçlandırmaların miktarı artmıştır (Evans, 2009; Alan, 2020). Gelinen noktada, dünyadaki toplam orman alanının \%7'sini oluşturan ağaçlandırmalar, odun hammaddesi üretiminin yaklaşık \%50'sini karşılar duruma gelmiştir (Alan, 2020; FAO, 2020). Dolayısıyla, dünyadaki odun hammaddesi gereksiniminin karşılanmasında ağaçlandırmalar ormancılık yönetiminin ayrılmaz parçası olmuştur. Diğer yandan günümüzde ağaçlandırmalar, su ve toprak koruma, karbon tutma vb. işlevler için de oldukça önemli duruma gelmiştir.

Amerika Birleşik Devletleri (ABD)'nin güney eyaletlerinde yoğun bir şekilde ağaçlandırmalar yapılmaktadır. ABD'nin güney eyaletleri; Alabama, Arkansas, Delaware, Florida, Georgia, Louisiana, Mississippi, North Carolina, Oklahoma, South Carolina, Tennessee, Texas ve Virginia'dan oluşmakta ve bu eyaletlerde yaklaşık 16 milyon ha alanda ağaçlandırma yapılmaktadır (Hugget ve ark., 2013). Bununla birlikte ağaçlandırmalar, eyaletlerin tamamında aynı yoğunlukta sürdürülmemektedir.

ABD'deki toplam ağaçlandırmanın \%75'ini oluşturan güney eyaletlerindeki ağaçlandırmalar, araştırmalara dayalı olarak, bilimsel bir zeminde üniversiteler ile iş birliği halinde şirketler ve devlet orman işletmelerinden oluşan kooperatifler eliyle yürütülmektedir (McKeand ve ark., 2003). 1950'lerde başlayan çalışmalar sonucu, güney eyaletleri, odun deposu (wood basket) olarak adlandırılmış ve dünya odun hammaddesi üretiminin yaklaşık \%15'ni karşılar hale gelmiştir (McKeand ve ark., 2003, Fox ve ark., 2007).

Türkiye'de de 1950'lerden bu yana ağaçlandırmalar yapılmaktadır. Başlangıcından günümüze kadar ortalama olarak yaklaşık 34000 ha/yıl ağaçlandırma yapıldığ 1 ve ağaçlandırma miktarının toplam ormanlık alanın \%10'nu geçtiği görülmektedir (OGM, 2020). Bu konuda, ağaçlandırmanın ve ağaç 1slahının önemini anlatan ve öneriler geliştiren yayınlar bulunmakta, ayrıca ağaçlandırma konusu ormancilıkla ilgili politikalar, kalkınma planları ve stratejik planlarda yer almaktadır (OGM, 2004; ÖİK, 2014; OGM, 2018). Ancak, karar vericiler (başta Orman Genel Müdürü olmak üzere üst düzey yöneticiler), uygulayıcılar (başta ağaçlandırma programlarını arazide uygulayan
Orman Mühendisleri - Ağaçlandırma Şefleri- olmak üzere, Orman Bölge Müdürleri, Orman İşletme Müdürleri, Orman Fidanlık Müdürleri, Orman Ağaçları ve Tohumları Islah Araştırma Enstitüsü Müdürlüğü ve başka kurumlar bünyesinde ağaç 1slahı çalışmalarını yürüten teknik ekipleri) ve ormancılık sektörü (başta odun hammaddesini girdi olarak kullanan kuruluşlar- şirketler- olmak üzere, ormancılıkla ilgili tüm kuruluşlar) arasında, sürdürülebilir bir ağaçlandırma konusunda fikir birliği sağlanamadığı ve ağaçlandırma çalışmalarının da bu doğrultuda uygulamaya konulamadığ1 görülmektedir. Bu kapsamda uygulamacıların, sürece yeterince katk1 koyamadıkları, orman sanayii sektörünün (şirketler) ise uygun maliyetle orman ürünleri sağlanamadığını öne sürmeleri dikkati çekmektedir. Oysa ağaçlandırmaların, yukarıda sayılan tüm paydaşların büyük oranda benimsemesiyle, dünyada pek çok ülkede olduğu gibi ormancılık yönetiminin ayrılmaz bir parçası olarak, sürdürülebilir bir yapıya kavuşturulabilmesi olasıdır.

Ağaçlandırma konusunda Türkiye'de 1950'lerden bu yana oluşmuş birikim kullanılarak, paydaşlarca benimsenmiş ve ormancılık yönetimin ayrılmaz bir parçası olmuş ağaçlandırılmalar, odun hammaddesi üretimine önemli katkılar sağlayacak ve doğal ormanlar üzerindeki bu yöndeki baskıların azalmasına yol açacaktır. Bu kapsamada, ABD’nin güney eyaletlerinde başarılı bir şekilde yürütülen ağaçlandırma çalışmaları incelenerek, Türkiye'de yürütülen ağaçlandırmalar açısından irdelemek ve ağaçlandırmanın, ormancılık yönetiminin ayrılmaz bir parçası olması yönünde katkı sağlamak amaçlanmıştır.

\section{Ağaçlandırmaların Ormancılıktaki Yeri}

Dünyada ağaçlandırmalarla ilgili kayıtların MÖ 4000 yıllarına ait olduğu, odunsu bir bitki olan zeytinin seçilmesi ve dikilmesi ile ilgili olduğu öne sürülmüş, bu kapsamda ağaçlandırmalar da, 1900 öncesi, 1900-1945, 1945-1980 ve 1980 sonras1, olmak üzere dört ana bölümde incelenmiştir (Evans, 2009). Bu gelişim sürecinde ise oluşan bilgi birikimi, artan gereksinimler sonucu 1980'li yıllardan sonra ağaçlandırmalar daha fazla gündeme gelmeye başlamış ve odun hammaddesi üretimindeki payının vazgeçilmez olduğu anlaşılmıştır (Evans, 2009; Alan 2020). Tarihsel olarak bakıldığında ise ağaçlandırmaların doğal ormanlardan sağlanan endüstriyel odun üretimine destek amacıyla başlatıldığ düşünülmektedir (Onyekwelu ve ark., 2011).

Ağaçlandırmaların dünyadaki toplam alanı 294 milyon ha'a ulaşmıştır (FAO, 2020). Bu kapsamda, ağaçlandırmalardan üretilen endüstriyel odun (round wood) miktarı toplam üretimin yakla- 
Ş1k \%50'sine, hatta ABD’nin güneyinde yaklaşık \%90’ına ulaşmıştır (Payn ve ark., 2015; Alan, 2020). Carle ve Holmgren, (2009), dünyada 2030 yılında ağaçlandırma alanlarının 263-303 milyon ha olabileceğini tahmin etmişlerdir. Ağaçlandırmada günümüzde ulaşılan 291 milyon ha göz önüne alındığında, Carle ve Holmgren (2009) tarafından yapılmış tahminin alt sınırının geçildiği (263 milyon) ve üst sınırına (303 milyon) çok yaklaşıldığ1, dolayısıyla 2030 yılında bu rakamın çok üzerine çıkılabileceği görülmektedir. Buna koşut olarak ağaçlandırmaların üretimdeki paylarının daha da artacağ1 ve \%50'lerin üzerine çıkacağ1 anlaşılmaktadır.

Ağaçlandırmalar, endüstriyel veya diğer amaçlarla yapilabilmektedir. Bu kapsamda, Onyekwelu ve ark. (2011), dünyadaki ağaçlandırmaların \%80'inin endüstriyel ağaçlandırmalardan (biçmelik, kaplamalık ve kâğ 1 t hamuru vb.) ve \%20'sinin ise endüstriyel olmayan ağaçlandırmalardan (yakacak odun veya odun dışı ürünler, toprak ve havza koruma vb.) oluştuğunu öne sürmektedirler. Diğer bir deyimle endüstriyel ağaçlandırmalar üretim amaçl1/verimli ağaçlandırmalar (productive forest plantations), endüstriyel olmayan ağaçlandırmalar ise koruyu$\mathrm{cu}$ ağaçlandırmalar (protective forest plantations) olarak da adlandırılmaktadır. Ülkemizde, Boydak ve Çalışkan (2014) ağaçlandırmaları öncelikle "Üretim amaçlı ağaçlandırmalar", "Koruma amaçlı ağaçlandırmalar" ve "Çevre düzenleme (estetik) amaçlı ağaçlandırmalar” olarak üç ana gruba; üretim amaçlı ağaçlandırmaları ise "odun üretimi”" ve "odun dişı üretimi” olarak 2 alt gruba ayırmış ve endüstriyel ağaçlandırmaları odun üretimi amaçlı ağaçlandırmalarda göstermişlerdir.
Ağaçlandırmalar kuruluşundan hasadın yapılmasına kadar planlama ve uygulama aşamalarından oluşmaktadır. Bu planlama ve aşamaların kullanılan tür, iklim, toprak ve bölgesel/ülkesel koşullara göre değişmesi çok doğaldır. Bu kapsamda, Onyekwelu ve ark. (2011) ağaçlandırmalarda izlenebilecek aşamalardan söz etmişlerdir. Bunlar;

a. Amacın belirlenmesi ve amaca uygun tür seçimi b. Türe uygun alanların belirlenmesi/eşleştirilmesi c.Üretim materyali kaynaklarının belirlenmesi ve islahi

d. Üretim materyalinin toplanması, depolanması ve çoğaltılması (fidanlık)

e. Arazi hazırlığı ve ağaçlandırmanın kuruluşu (dikim)

f. Bakım (gübreleme, aralama ve budama)

g. Hastalık ve zararlılara karşı koruma

h. Hasat ve yeniden ağaçlandırmadır.

Görüleceği üzere en başta ağaçlandırmaların bir amacının olması ve bu amaca uygun bir tür seçilmesi gerekmektedir. Seçilen türe uygun alanların, türle eşleştirilmesi (belirlenmesi değil), ağaçlandırma amacı kadar önemli bir aşamadır. Eşleştirme (matching) ile ağaçlandırma amacına uygun olarak seçilmiş türün, yetişme isteklerine (ekoloji) uygun alanlarda yetiştirilmesi kastedilmektedir. Eşleştirme, tür ile ağaçlandırılan alandan en çok verim almayı sağlarken, eşleştirme yapılmadığı (tür isteklerine uygun alanlarda yetiştirilmediği) durumlarda ağaçlandırmanın başarısız olacağı çok açıktır.

Ağaçlandırma aşamaları göz önüne alındığında, ilk iki aşamanın ağaçlandırma için belirleyici olduğu, diğer aşamaların ise ağaçlandırma için vaz-

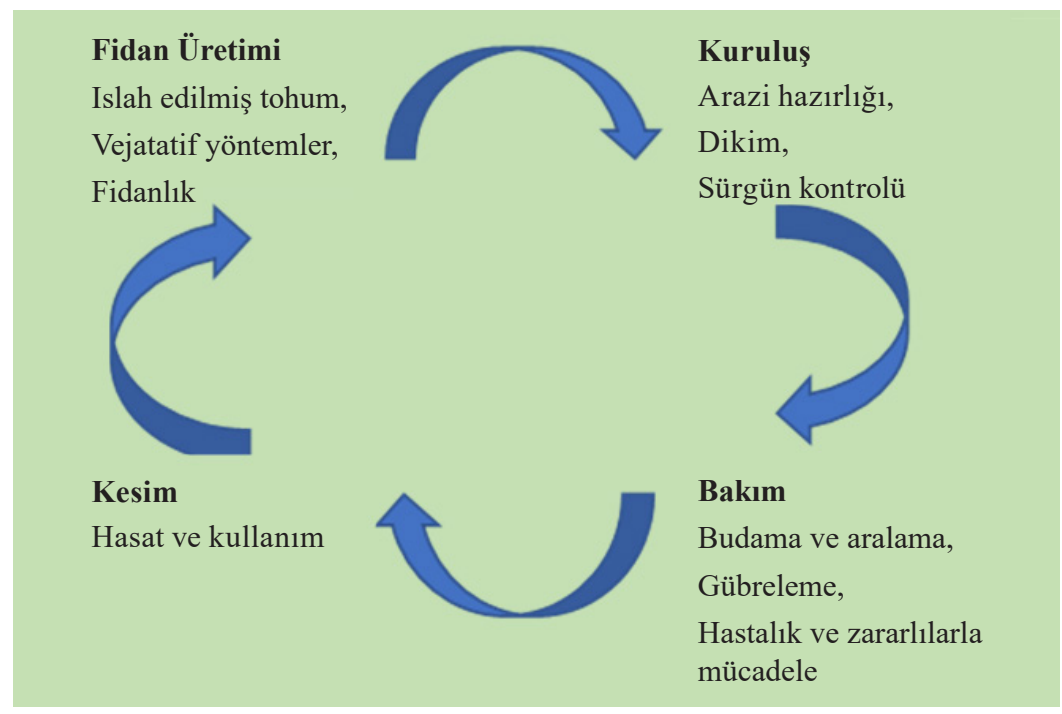

Şekil 1. Ağaçlandırmalarda fidan üretimi ile başlayan ve hasat ile sonuçlanan döngü (Mead, 2013)

Figure 1. The cycle that starts with seedling production and ends with harvest in planted forest (Mead, 2013) 
geçilmez aşamalar olmakla birlikte, daha çok tamamlayıcı (teknik özellikte) aşamalar olduğunun altı çizilmelidir. Diğer yandan ağaçlandırmaların sürdürülebilir olabilmesi için Şekil 1'de görüldüğü gibi döngüsel bir süreç izlemesi gerekmektedir (Mead, 2013). Böylece ağaçlandırmalar kendilerinden beklenen amacı sürekli bir biçimde karşılamış olacaklardır.

\section{ABD'nin Güney Eyaletlerinde Ağaçlandırmalar}

ABD’nin güney eyaletlerinde ağaçlandırmalarda kullanılan ağaç türleri Pinus teada, P. elliottii var. elliottii, $P$. palustris ve diğer türler olup, ağaçlandırmalardaki fidan kullanımı oranları ise aynı sırayla $\% 84, \% 11, \% 2$ ve $\% 2$ olduğu belirtilmiştir (McKeand ve ark., 2003). Görüleceği üzere, ağaçlandırmaların çok büyük bir oranı Pinus teada ile yapılmaktadır. Ağaçlandırmaların büyük çoğunluğu ise kooperatif üyeleri şirketler tarafından gerçekleştirilmektedir. Bu kapsamda 1990'larda Pinus teada, dünya üzerinde "yılda en çok dikilen ağaç" konumuna sahip olmuştur (Işık, 1991). Benzer biçimde, son yıllarda Pinus teada y1lda 400.000 ha'ın üzerinde ağaçlandırma yapılan bir tür durumuna gelmiştir (McKeand, 2017).

Ağaç 1slahı, toplumun gereksinimlerini daha iyi karşılamak için orman genetiğini kullanarak ağaçlandırmalarda en iyi materyali üretmeyi amaçlamaktadır (Ruotsalainen, 2014; Alan, 2020). Ağaçlandırmalarda en iyi genetik materyalin kullanımı ise birim alandan üretilen odun hammaddesinin hem miktarı hem kalitesini artırmaya hizmet etmektedir. Daha açık bir anlatımla, seçilmiş olan ağaç yaşamı boyunca, büyüme (hacim) ve kalitenin artmasına yönelik genlerini, daha etkin kullanmaktadır. Bu nedenle, dünyada yapılan ağaçlandırmalarda, ağaç ıslahı pek çok ülkede yaygın olarak kullanılmaktadır.

ABD’nin güney eyaletlerinden birisi olan North Carolina üzerinden ormanlara mülkiyet açısından bakıldığında, ormanların \%58'nin bireyler, aileler ve kurumsal düzeyde olmayan ortaklıklara, \%20 'sinin odun ürünü işleyen kuruluşu olmayan şirketlere, $\% 5$ 'inin orman endüstrisi olan şirketlere ve $\% 17$ 'sinin eyalete (devlet) ait olduğu görülmektedir (Troxler, 2017). ABD'nin güney eyaletlerinde ağaç 1slahı, ağaçlandırmaların en önemli bileşenlerinden birini oluşturmaktadır. Ağaçlandırmaların tamamına yakını da ıslah edilmiş fidanlar ile yapılmaktadır. Bu kapsamda, a- Florida Üniversitesi Orman Genetiği Araştırma Programı Kooperatifi (The Cooperative Forest Genetics Research Program at the University of Florida- https://programs. ifas.ufl.edu/cfgrp) b- Texas Orman Kurumu Batı Körfezi Ağaç Islahı Programı (The Western Gulf
Forest Tree Improvement Program at the Texas Forest Service-https://tfsweb.tamu.edu/WesternGulfForest) ve c- Kuzey Karolina Eyalet Üniversitesi-Endüstri Koopreatifi Ağaç 1lsahı Programı (the North Carolina State University-Industry Cooperative Tree Improvement Program or NCSU TIP -https://www.treeimprovement.org) olmak üzere üç adet kooperatif (ortaklık) şeklinde 1slah programı yürütülmektedir (McKeand ve ark., 2003; Fox ve ark., 2007). Bu programların üyeleri, devlet (orman işletmeleri) ve özel (şirketler) kuruluşlardan oluşmaktadır. Islah programlarında üniversitelerin yer alması, araştırmalara önem verildiğini ve çalışmaların bilimsel bir temele dayalı olarak yürütüldügüüü göstermektedir. Çalışmaları çok başarılı duruma getiren bu yapidan (kooperatif) dolayı da Işık (1991) tarafından da belirtildiği gibi NCSU TIP, ağaç 1slahında dünyada öncü konumunu sürdürmektedir.

ABD'nin güney eyaletlerinde yapılan ağaçlandırmalarda en çok kullanılan Pinus taeda, hızlı büyüyen bir ağaç türü olup, yoğun bir şekilde islah edilmektedir. Ayrıca ABD'nin güney eyaletlerinde iklim koşullarının (yağış, sıcaklık ve vejetasyon süresi), yanı sıra arazi koşulları (ortalama eğim \%0'a yakın, topraklar oldukça verimli) da bu tür için oldukça uygundur (Şekil 2). Bu etkilerin birleşiminin bir sonucu olarak, "orman ürünleri endüstrisi” ekonomik olarak, ABD’nin güney eyaletlerinden birisi olan North Carolina'nın en büyük, ABD'nin ise ikinci büyük sektörü olmuştur (Troxler, 2017).

ABD’nin güney eyaletlerinde ağaçlandırmalar, 1950'li yıllarda başlamış ve o tarihlerde yaklaşık 810.000 hektar (ha) olan ağaçlandırma miktarı, 13.000.000 ha'a ulaşmış, benzer biçimde $6 \mathrm{~m}^{3} / \mathrm{ha}$ olan yıllık artım da yaklaşık 5 kat artarak, $28 \mathrm{~m}^{3} /$ ha'ın üzerine çıkmıştır (Fox ve ark., 2004). Ağaçlandırma alanlarında görülen bu artış eğilimi sürmüş ve ağaçlandırma alanları, orman alanlarının \%19'una yükselerek 15.800.000 ha olmuştur (Hugget ve ark., 2013). O nedenle ABD'nin güney eyaletleri, ABD'nin odun hammaddesi üretimindeki önemini giderek artırmaktadır (Fox ve ark., 2004; Mckeand, 2019).

ABD’nin güney eyaletlerinde ağaçlandırmalardan sağlanan artıma katkı yapan bileşenler, Stanturf ve ark. (2003) tarafından incelenmiştir. Buna göre 1950'li yıllarda ağaçlandırmalarda sağlanan yıllık artıma, stok kontrolünün (alandaki birey sayıs1) $\% 40$, fidan kalitesinin $\% 10$ ve toprak hazırlığının \%50 katkı sağladığı, günümüzde ise gübrelemenin $\% 35$, sürgün kontrolünün $\% 35$, ağaç ıslahının \%20 ve alan (arazi) eşleştirmesinin (türün isteklerine uygun alan) \%10 katkı sağladığ 1 


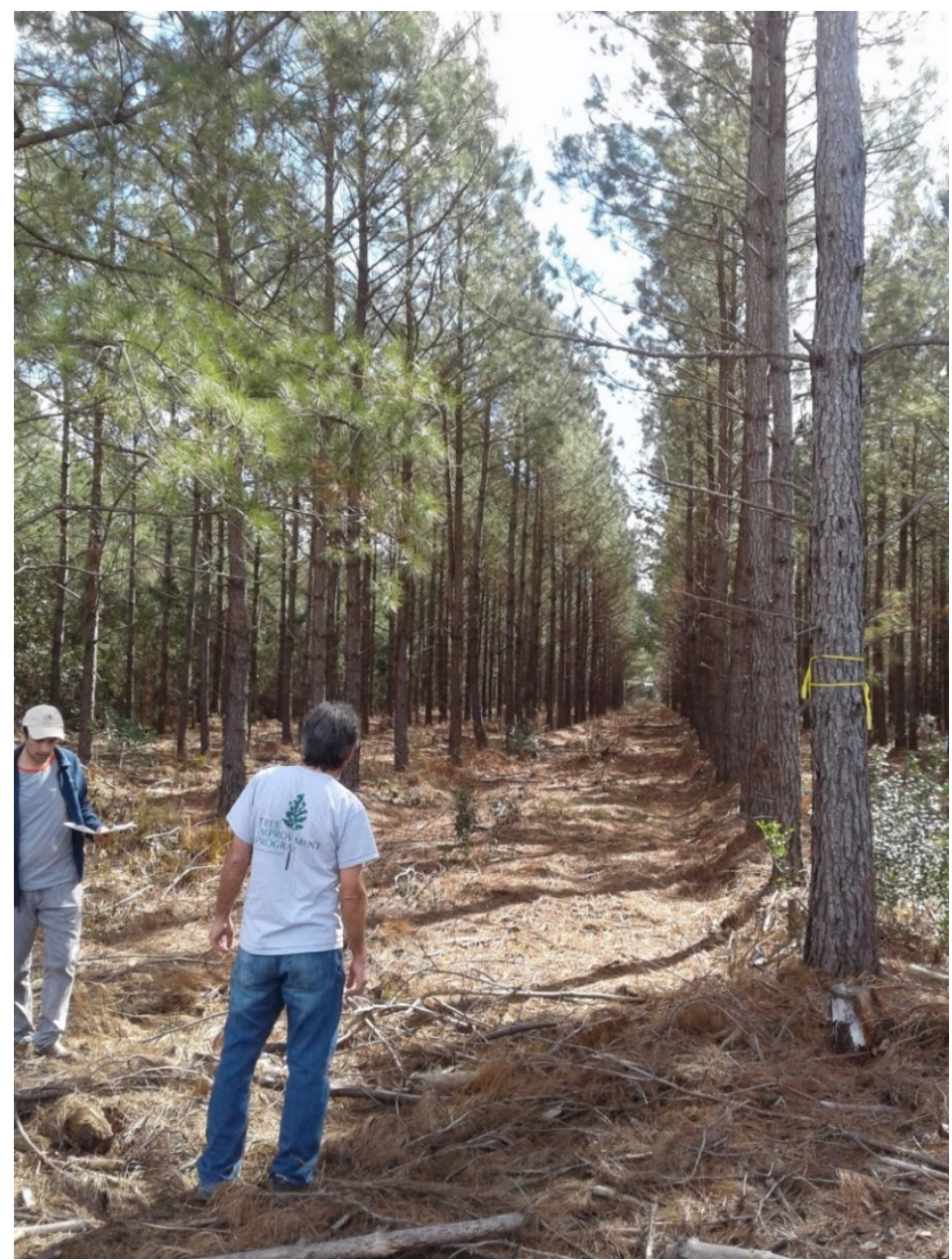

Şekil 2. Güney Carolina Eyaletinde bir Pinus taeda genetik kazanç (birim alandaki artış karşılaştırması) denemesi Sağdaki sıra (sarı bantlı) genetik yönden üstün bir aileyi, soldaki parsel ise 1slah edilmemiş materyali temsil etmektedir (Foto Fikret Işık)

Figure 2. Genetic gain (comparison of increase per unit area) trial on a Pinus taeda in the State of South Carolina The row on the right (yellow band) represents a genetically superior family, the left parcel represents the nonimproved material (Photo Fikret Işı1k)

belirtilmiștir. Günümüzde arazi hazırlı̆̆ı veya fidan kalitesinin artıma katkı sağlamadığ 1 söylenemez, ancak etkiler standart hale gelmiştir. Yani bir önceki ağaçlandırmaya göre sağlanan artımda örneğin gübrelemenin katk1 pay1 $\% 35$ olurken, arazi hazırlığının katkı payı değişmemiştir.

Yukarıda söz edildiği gibi yoğun silvikültür ve ağaç ıslahının kullanılması ile sağlanan birim alandaki artış, orman ağaçlarının idare süresinin (hasat yaşı) kısalmasına yol açmaktadır. ABD'nin güney eyaletlerinde de ağaçlandırmalarda başlangiçta (1940) 100 ton/ha olan biokütle (toplam servet) miktarı, ağaç ıslahı, gübreleme, arazi hazırlığının katkısı ve sürgün kontrolü uygulamalarının kullanımı ile 500 ton/ha (2010) üzerine çıkmıştır. Böylece birim alanda sağlanan bu artışın bir sonucu olarak 1940 'ta 50 yıl olan idare süresinin, 2010 yılında ağaçlandırmalarda 18 yıla inebilece- ği (Şekil 3) öngörülmüștür (Fox ve ark., 2004). Bu arada, idare süresinin 50 yıldan 18 yıla inmesinin ağaçlandırmalarda, odun üretimi için kullanılan yoğun silvikültürel (gübreleme gibi) yöntemler ile ağaç ıslahının etkili olduğunun altı çizilmelidir (Alan, 2020).

Ağaçlandırmalardan sağlanan verim artışında ağaç ıslahının etkisi oldukça önemlidir. Genomik seleksiyonun da ağaç ıslahında kullanılmasının gündeme gelmesi sonucu, ağaç ıslahının ağaçlandırmalardaki verim artışına katkısının daha da artması beklenmektedir (Isik ve Mckeand, 2019). Ağaç 1slahı çalışmaları generasyonlar (cycle) şeklinde ilerlemektedir (Şekil 4). Buna göre bir sonraki generasyonun genetik değeri bir öncekinden daha yüksek olmakta, dolayisıyla birim alandan üretimin de bir önceki generasyonda olduğundan daha yüksek olması sağlanmaktadır. Dünyadaki 


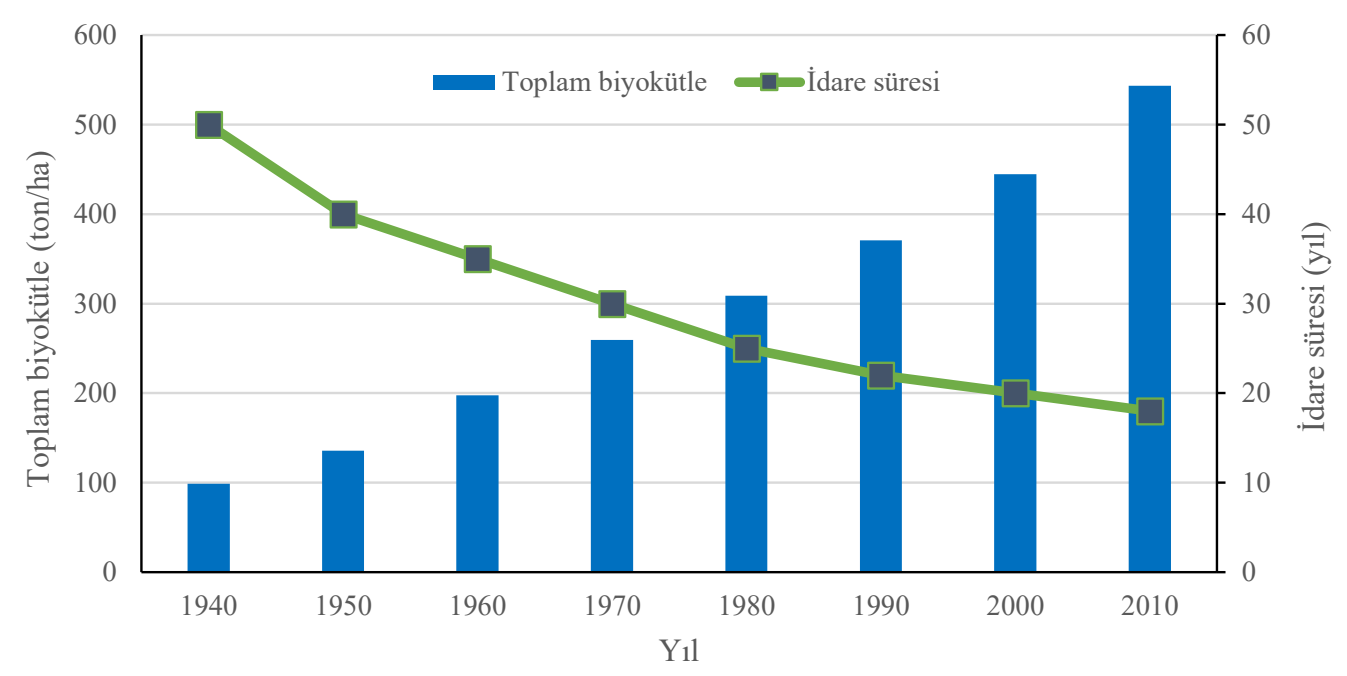

Şekil 3. Ağaçlandırmalarda biokütlenin (toplam servet) 1940'ta 100 ton/ha, 2010'da 500 ton/ha (mavi sütunlar) olmasına paralel olarak, idare süresi (yeşil çizgi) 50 yıldan 18 yıla inmiştir (Fox vd., 2004'ten alınıp metrik sisteme göre düzenlenmiştir)

Figure 3. Parallel to the fact that biomass (total stock) in afforestation was 100 tons / ha in 1940 and 500 tons / ha (blue columns) in 2010, the rotation age (green line) decreased from 50 years to 18 years (It was arranged to the metric system from Fox et al., 2004)

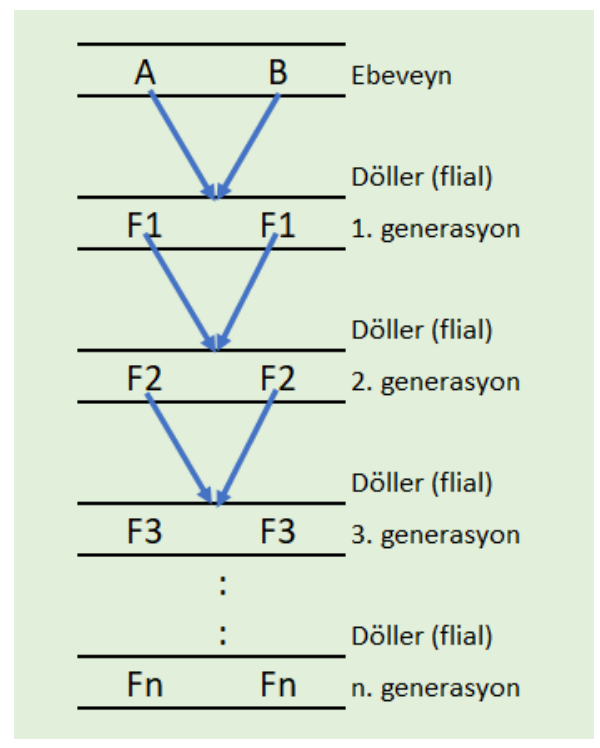

Şekil 4. Ağaç 1slahı döngüsünde generasyonlar. A ve B ebeveynlerinin döllenmesi ile F1 dölleri (birinci generasyon), F1 döllerininin en iyileri arasında döllenme yapılarak F2 dölleri (ikinci generasyon) elde edilmekte, generasyonlar bu şekilde sürdürülmektedir

Figure 4. Generations in the tree breeding cycle. By crossing of A and B parents, F1 progeny (first generation),

F2 progeny (second generation) are obtained by crossing among the best of $\mathrm{F} 1$ progeny, and the generations are continued in this way

ağaç ıslahı çalışmalarında en ileri aşamaya ulaşmış 1slah program olan NCSU TIP, Pinus taeda'da 5. generasyona ulaşmış ve 4. generasyon için islah edilmemiş materyale göre, hacim için $\% 63$ genetik kazanç (üretim artışı) beklenmektedir (Isik ve Mckeand, 2019; Mckeand, 2019). Yani 1slah edilmemiş tohum kullanıldığında ağaçlandırmalarda birim üretim $100 \mathrm{~m}^{3}$ ise 1 slah edilmiş tohum kullanıld1- ğında (4. generasyon genetik tohum bahçesi) birim üretim $163 \mathrm{~m}^{3}$ olacaktır.

Ağaç 1slahı sonunda üretilen materyal, tohum bahçeleri kullanılarak ağaçlandırmalara aktarılmaktadır. Bu kapsamda da ibreli türlerin hemen hemen tamamında tohum bahçesi kullanılmaktadır. NCSU TIP, her ıslah döngüsünü tamamladığında 
yeni tohum bahçelerinin kurulmasını sağlamaktadır. NCSU TIP Kooperatif ortakları ise ağaçlandırmalarında en ileri ıslah materyalini tercih etmektedirler. Yani yeterince 2. generasyon ürünü tohum varken, asla 1. generasyon ürünü tohum kullanılmamaktadır. Nitekim, kooperatif üyeleri, 1. generasyon tohum bahçelerinin, 2010 yılından itibaren ağaçlandırmalarda kullanılmasını bırakmışlar, 2., 3. ve üzeri generasyon tohum bahçeleri ile ağaçlandırmalarını sürdürmüşlerdir (NCSU TIP, 2020). Günümüzde kullanılan tohumun ise \%26's1 2. ge- nerasyon, \%74'ü 3. generasyon ve üstü (4. generasyon) tohum bahçelerinden toplanmıştır. Bunun nedeni ıslah edilmemiş materyal kullanımına göre, genetik kazancın (hacimde üretim artışı) yılda \%1 oranında artmasının, parasal değerinin 2,5 milyar dolar olmasıdır (McKeand ve ark., 2008; McKeand, 2015). Bu nedenle ABD'nin güney eyaletlerinde genetik değeri daha yüksek tohum üretebilmek için tohum bahçelerinde on binlerce kontrollü (yapay) dölleme (genetik değeri daha iyi aileler arasında yapılan dölleme) yapılmaktadır (Şekil 5).
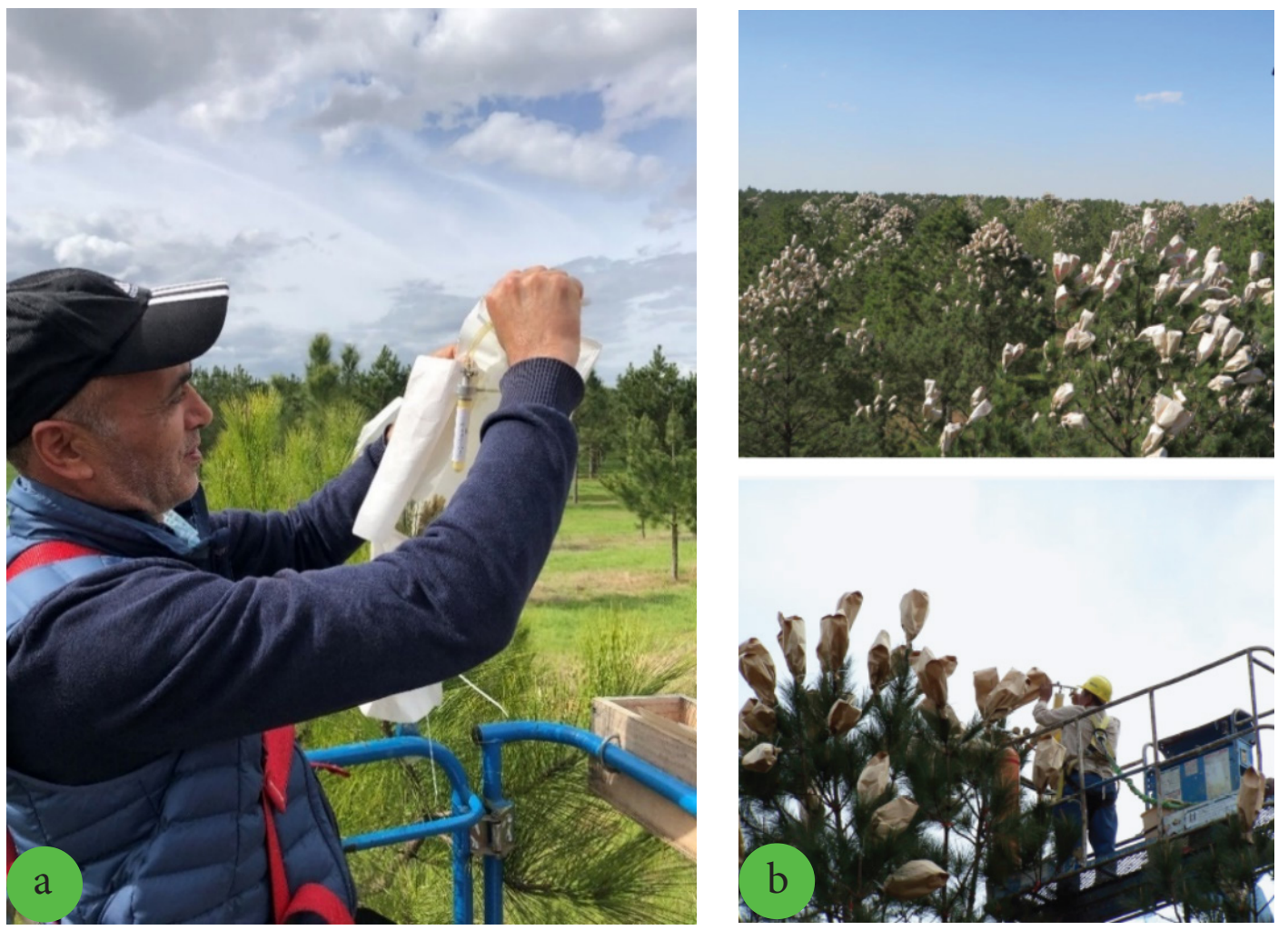

Şekil 5. Pinus taeda tohum bahçesinde yapay dölleme, (a) Georgia Eyaletinde bulunan 1slah merkezi (Foto Uğur Memiş), (b) yapay döllenmiş bir tohum bahçesinden genel görünüş ve yoğun yapay dölleme (McKeand, 2019) Figure 5. Control crossing in Pinus taeda seed seed orchard, (a) breeding center in Georgia State (Photo Uğur Memiş), (b) general view of seed orcrhard with control crossing and mass control crossing activity (McKeand, 2019)

\section{Türkiye'de Ağaçlandırmalar}

Türkiye'de ağaçlandırmalar 1946 yılında başlamakla birlikte, 1966 yılında yapılan "Orman Mühendisliği I. Teknik Kongresi” ve ağaçlandırmanın kalkınma planı içinde yer almasından sonra ivme kazandığ 1 belirtilmiştir (Boydak ve Çalışkan, 2014; OGM, 2020). Bu çerçevede, 1946-2019 yıllarında yapılan ağaçlandırmaların toplam miktarı 2,5 milyon ha'a ulaşmış ve yıllık ortalama ağaçlandırma ise 33.545 ha olmuştur (Şekil 6). Yıllık ağaçlandırmanın en yüksek olduğu yıl 1988 (119.369 ha) olurken, son 10 yılda ise 2019 yılı (17.861 ha) dikkate alınmazsa yıllık ortalama yaklaşık 40.000 ha ağaç- landırma yapılmıștır (OGM, 2020).

Bugüne kadar yapılmış 2,5 milyon ha ağaçlandırmanın türlere göre dağılımına ilişkin bir veriye ulaşılamamıştır. Yaklaşık \%40'nın, yani 1 milyon ha'nın kızılçam ile yapıldı̆̆ı varsayılmaktadır. Diğer yandan 2009-2019 yılları arasında, ağaç türlerine göre ortalama fidan üretimi de ağaçlandırmaların büyük çoğunluğunun, yapraklıları saymazsak, karaçam, sedir, kızılçam, sarıçam türlerinde yapıldığını göstermektedir (Şekil 7). Üretimin tamamının ağaçlandırmalarda kullanılmadığını dikkate alınarak, 2009-2019 yılları arasında, ortalama olarak, karaçam, sedir, kızılçam ve sarıçam 
türlerinde sirasiyla, 75, 57, 48 ve 41 milyon adet, toplam fidan ortalamasinın ise 368.2 milyon adet olduğu saptanmıştır (OGM, 2020). Türkiye'de bugüne kadar kurulmuş tohum bahçeleri de daha çok ağaçlandırmaların yapıldığı bu türlerde kurulmuş ve alan olarak kızılçam tohum bahçeleri 650 ha ile birinci sırada yer almıştır (OATIAM, 2020). Nitekim, Türkiye Ormancılar Derneği (ormancilardernegi.org) tarafından hazırlanan ve çoğunlukla uygulamacıların önemli katkılar sağladığı,
“Endüstriyel Ağaçlandırma Eylem Planı” üzerine kapsamlı raporda da kızılçamın özellikle endüstriyel ağaçlandırmalardaki ağırlığı vurgulanmıştır (TOD, 2019).

Türkiye'de ağaç ıslahı çalışmalarında dünya standartlarında bir altyapı bulunmakta ve yapılan araştırmalar, ıslah çalıșmaları sonucu, kızılçamda birim alanda, hacimde \%25-30'a ulaşan artış sağlanabileceğini göstermektedir (Öztürk ve Şıklar,

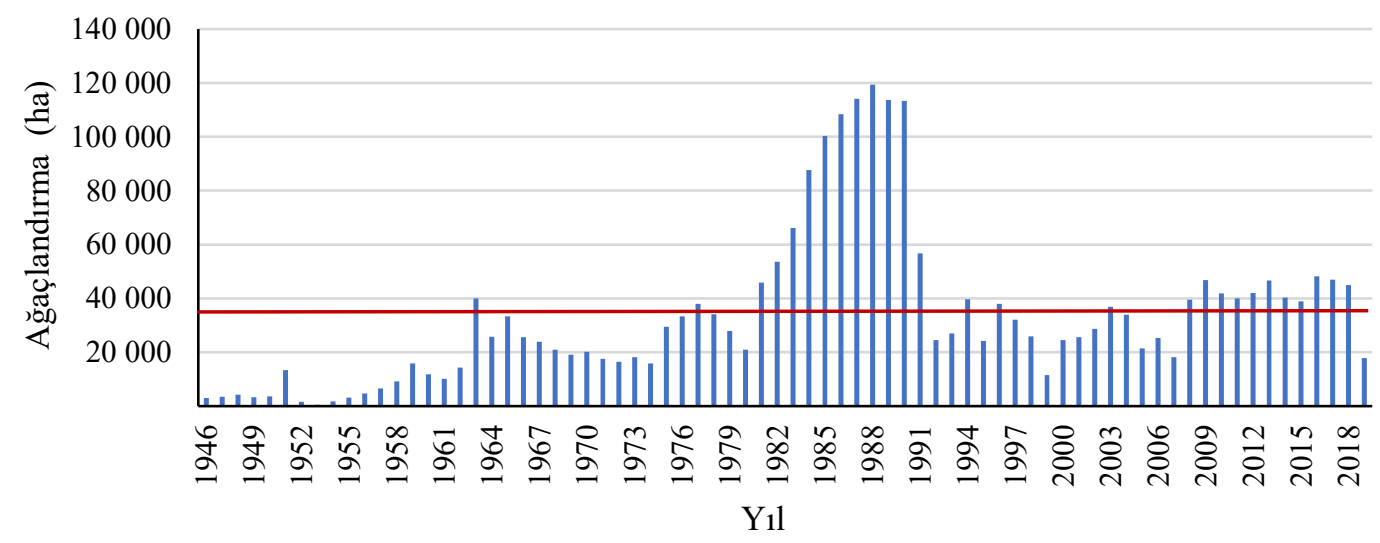

Şekil 6. Türkiye'de 1946-2019 yılları arasında yapılan ağaçlandırmalar (OGM, 2020), yıllık ortalama (kırmızı çizgi) 33.545 ha

Figure 6. Planted forests in Turkey between the years 1946-2019 (OGM, 2020), the annual average (red line) 33.545

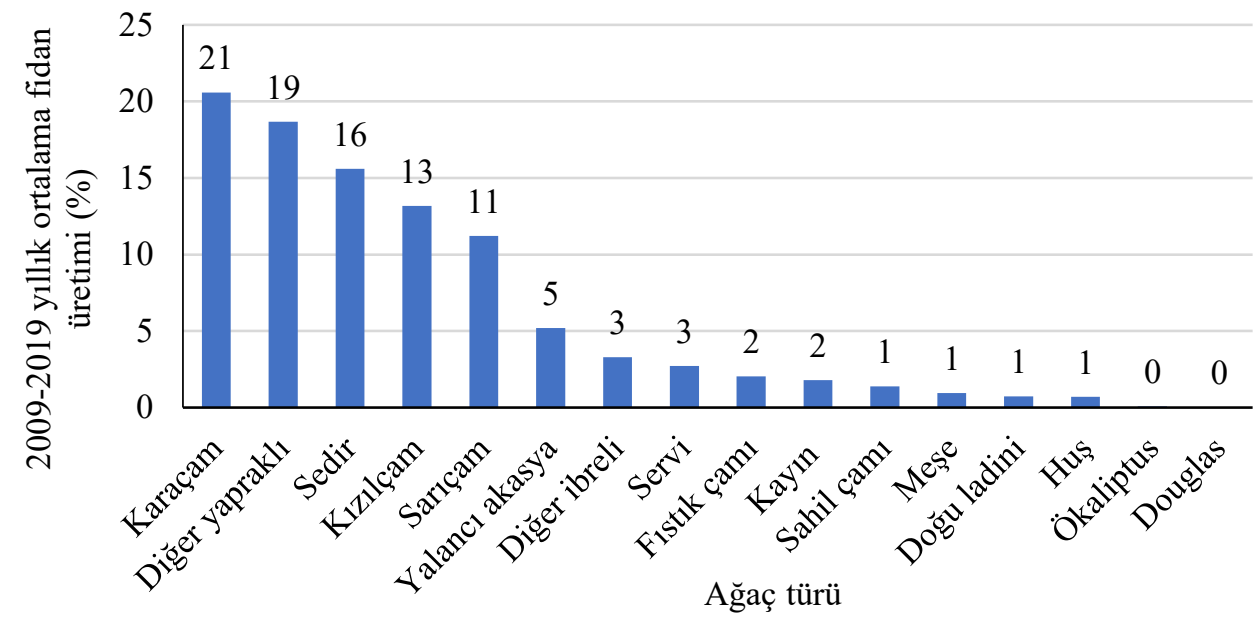

Sekil 7. Türkiye'de 2009-2019 yılları arasında ağaç türlerinde yıllık ortalama fidan üretimi (OGM, 2020) Figure 7. Mean annual production of seedlings of tree species in Turkey between the years 2009-2019 (OGM, 2020)

2000; Ş1klar ve Öztürk, 2009; Alan, 2012; Alan ve ark., 2012; Ş1klar ve ark., 2017). Iş1k (1991) de kızılçamın, Pinus teada gibi ıslah edilerek, Türkiye'de ağaçlandırmalarda yaygın olarak kullanılmasını önermiştir. Bu kapsamda mevcut alt yapı ve personel desteklenerek, genetik değerleri daha yüksek bireyleri üretmek için kızılçamda yapay döllemeler kullanılarak, 2. generasyon sslah ça- lışmalarını başlatmak olasılık dahiline girmiștir. Böylece ABD’nin güney eyaletlerinde Pinus tae$d a$ 'da olduğu gibi ıslah çalışmaları ile kızılçamda birim alanda ulaşılan \%25-30 hacim artışı daha da yükseltilebilir.

Kızılçam yanında, sahil çamı (Pinus pinaster), kavak (Populus sp.) ve okaliptüs (Eucalyptus sp.) 
türlerinde de ıslah çalışmaları yapılmaktadır. K1zılçam dışında kalan türlerde yapılan ağaç ıslah çalışmaları, kızılçam seviyesine ulaşmamıştır. Dolayısıyla, Endüstriyel Ağaçlandırma Eylem Planında ağaçlandırma hedefleri, kızılçam \%88 (yaklaşık 145.000 ha), sahil çamı \%8,5 (yaklaşık 14.000 ha), kavak \%0,7 ve okaliptüs \%0,7 (yaklaşık 1000 ha) olarak belirlenmiş, ıslah çalışması yapılmamış olan dişbudak ise \%2,1 (yaklaşık 3.400 ha) pay almıştır (OGM, 2013).

Türkiye'de ıslah çalışmalarının ağaçlandırmalara aktarılmasını sağlayan tohum bahçeleri kuruluşunda iyi bir noktaya ulaşılmıştır. Ayrıca endüstriyel ağaçlandırmalarda en ağırlıklı tür olan kızılçamda ise döl denemeleri sonucuna göre kurulmuş, yani genetik değeri daha yüksek olan, dolayısıyla birim alandan daha çok artış sağlayabilecek 80 ha tohum bahçesi bulunmaktadır (OATIAM, 2020). Dolayısıyla, kızılçam, karaçam ve sarıçam tohum bahçelerinden üretilen tohumlar bu türlerde yapılan ağaçlandırmalar için yeterlidir (Koski ve Antola, 1994; OATIAM, 2020). Ancak en üst düzeyde tohum üretebilmek için tohum bahçelerinde bakım ve koruma (tohum bahçesi yönetimi) önlemlerinin alınması, tohum bahçelerindeki tohumların tamamının toplanması ve tohum dağıtımı konusunda iyi bir planlamanın yapılması gereklidir.

Türkiye'de ağaçlandırma ve ağaç 1slahı konusunda sağlanan önemli birikimlere karşın bazı eksiklikler henüz giderilememiştir. Giderilemediği düşünülen eksiklikler aşağıda açıklanmıştır.

1-Ăgaçlandırmaların odun üretimi açısından değerlendirilmesi veya doğal ormanlar ile karşllaştırılmasının yapılamaması. Kızılçam için Usta (1991) ve Erkan (1996) tarafından yapılan hasılat araştırmaları, I. bonitet doğal ormanlarda $10 \mathrm{~m}^{3} /$ ha, ağaçlandırmalarda ise $15 \mathrm{~m}^{3} /$ ha yıllık artım gerçekleştiğini göstermiştir. Türkiye'deki doğal ormanlarda yıllık artımın $2 \mathrm{~m}^{3} /$ ha olduğu belirtilmiştir (TOD, 2019). Benzer biçimde Türkiye'de yapılmış olan 2,5 milyon ha ağaçlandırma için böyle bir bilgi bulunmamaktadır. Bu bakımdan ayrı örnekleme yapılarak amenajmanının yapılması, Türkiye'de bugüne kadar yapılan ağaçlandırmaların değerlendirilmesi ve mevcut durumun ortaya konulmasında yarar bulunmaktadir. Mevcut durum ortaya konulduğu takdirde maliyeti yüksek ve uzun dönemli yatırımlar olan ağaçlandırmaların ekonomik olarak da değerlendirilmesi sağlanmış olabilecektir (Özel ve ark., 2017; Erkan ve ark., 2020).

2-Ağaçlandırma yapılacak alanların, net bir biçimde belirlenmemesi (tahsis), ağaçlandırmaya ayrılmış (tahsis) alanlarının en azından harita üzerinde sınırlarının çizilememesi. Türkiye'de ağaçlandırmaların hemen tamamı devlet ormanlarında gerçekleşmektedir. Ormanlardan sorumlu Orman Genel Müdürlüğü (OGM), ağaçlandırma için hangi alanların ayrıldığ 1 ve bu alanların hangi türlerle ağaçlandırılacağını uzun süreli olarak belirlediğinde, karar vericiler, uygulayıc1lar ve ormanc1lık sektörü önlerini görebilirler ve özellikle ormancılık sektörü yatırım ve planlarını ona göre yapabilir. Özellikle endüstriyel ağaçlandırmalarda, tarımda olduğu gibi yoğun silvikültürel faaliyetlerin (sulama, gübreleme gibi) yapılabilmesi ve böyle uygulamalarda su havzalarının kirletilmemesinin de dikkate alınabilmesi için de alanların belirlenmiş olması gerekmektedir. Diğer yandan belirlenmiş ve sınırları çizilmiş alanlarda ağaç ıslahı çalışmalarının da daha az maliyetle ve daha etkili biçimde yapılabilmesi mümkün olacaktır. Örneğin, mevcut yapıda, Kızılçam ıslah zonlarından birisi olan Ege Bölgesi 0-400 m yükseltiler arasında ne kadar orman varsa bu alan için sslah çalışmaları yürütülmektedir. Oysa bu zonda ağaçlandırmaların sınırı ve yerleri belirli olursa, ıslah çalışmaları ağaçlandırma alanlarını göre, daha küçük çapta ve birim artışın daha yüksek olmasını sağlayacak biçimde yapılabilecektir.

3-Ağaçlandırmaların planlanma sürecinin yeterince değerlendirilememesi, planlama (etüt proje) sürecinin hızl tamamlanması ve çoğunlukla eksiklikler içermesi. Uygulamacıları en çok tedirgin eden noktalardan birisi planlama sürecidir. Çünkü, planlamadan kaynaklanan aksaklıklar, doğrudan uygulamacılara sorun olarak yansımaktadır. Diğer yandan çok kısa sürelerle ağaçlandırma ölçütlerinin dolayısıyla da ağaçlandırma alanlarının önemli ölçüde değişikliğe uğradığı ve planlama sürecinin ister istemez bundan etkilendiği anlaşılmaktadır. Örneğin Endüstriyel Ağaçlandırma Eylem Plan1 (2013-2023)'nda 165.000 ha (OGM, 2013) olan ağaçlandırma alanı aynı dönemi kapsayan OGM Stratejik Planında (2019-2023) iki katına çıkarılarak, 330.000 ha (OGM, 2018) olmuştur. Bu iki veriden hareketle, planlama ölçütlerinin alanı iki kata çıkaracak şekilde iyileştiği varsayılmaktadır. $\mathrm{Bu}$ durumda ağaçlandırma kapasitesinin de doğal olarak iki kat artması beklenmektedir. Oysa yukarıda belirtildiği üzere Türkiye'de tüm türlerle yapılabilen yıllık ağaçlandırma miktarı 33.545 ha olup, son yıllarda ortalama yıllık ağaçlandırmanın ise 40.000 ha düzeyine yükseldiği görülmüştür. Yani 10 yıldır kapasitenin değişmediği anlaşılmaktadır. Kapasitenin iki kat artırılması demek aynı zamanda, uygulayıcı personelin, kullanılan ekipmanın, işgücünün ve ağaçlandırmalarda kullanılacak ıslah edilmiş materyalin iki katına çıkarılması anlamına gelmektedir. Eğer planlamada, tüm bunlar dikkate alınmışsa, ağaçlandırma alanının iki katına çıkarılması doğal bir süreç olacaktır. Ancak planlama 
süreci iyi değerlendirilmeden ve altyapı olmadan, sadece ağaçlandırma alanı artırılırsa 20-30 yıl boşa gitmiş olacak, ağaçlandırma amaçları da yerine getirilememiş olacaktır.

4-Türkiye'de odun ürünleri (tomruk, lif yonga, kağıtlık odun vb.) taleplerinin belirlenmemiş olmast. Kısa, orta ve uzun dönemli talepler belirlendiğinde, ağaçlandırma amaçlarının daha gerçekçi ve taleplere uygun olarak planlanması sağlanabilecektir. Örneğin ince çaplı ürünlere daha çok gereksinim olduğu varsayıldığında, kızılçam ile dar aralık mesafe ve kısa idare süreli ağaçlandırmalar yapılarak, bu talep daha hızlı biçimde karşılanabilecektir. Böylece ağaçlandırmalar taleplerin karşılanmasında daha etkin biçimde kullanılabilecektir. Bu kapsamda orman ürünleri talebinin belirlenmesi konusunda, OGM bünyesinde bölgesel düzeyde konumlanmış Ormancılık Araştırma Enstitüsü Müdürlüklerinden etkin bir şekilde yararlanılabileceği düşünülmektedir.

\section{5-Ağaçlandırmalar konusunda yapılan} araştırmaların değerlendirilmemesi veya gerekli araştırmaların yapılamaması. Türkiye'de Ulusal Ormancılık Programı (OGM, 2004), Kalkınma Bakanlığının Ormancılık Özel İhtisas Komisyon Raporları (ÖİK, 2014) ve diğer resmî belgelerde (eylem planları, stratejik planlar) ağaçlandırmalar yer almasına ve hedefler belirlenmesine karşın, karar vericiler, uygulamacılar ve ormancılık sektörünün ortaklaştığı bir ağaçlandırma uygulaması gerçekleştiğini söylemek zordur. Ağaçlandırma konusunda ortaklaşma sağlamak için araştırmalar önemli bir çözüm noktası olabilecektir. Bu kapsamda belirsizlik içeren ve anlaşmazlık bulunan konular araştırılabilir ve sonuca bağlanabilir. Örnek olarak, "Endüstriyel Ağaçlandırma Eylem Planının” başladığı 2013 yılında, tartışılan ve üzerinde anlaşılamayan konular için araştırmalar başlatılmış olsaydı, konuların pek çoğu bugüne kadar, bilimsel olarak çözüme kavuşmuş olabilirdi. Aynı şekilde, Endüstriyel Ağaçlandırma Eylem Planı uygulaması çerçevesinde yaklaşık 5-6 yaşına ulaşmış ağaçlandırmalar üzerinde de gereksinim duyulan ve geleceğe yönelik araştırmalar başlatılması olasıdır.

\section{Sonuç}

Dünyadaki eğilime bakıldığında toplumun odun hammaddesi gereksinimini karşılamak için ağaçlandırmalar, ormancılık yönetiminin ayrılmaz bir parçası olarak ortaya çıkmaktadır. Bu kapsamda Türkiye'de hem ağaçlandırma hem de ağaç ıslahı açısından oldukça önemli bir birikim bulunmaktadır. Ağaç ıslahı sonucu geliştirilen üretim materyalleri, tohum bahçesi aracılığıla

\section{kullanılabilmektedir.}

Türkiye'de gösterilen tüm çabalara ve yapılan yayınlara karşın karar vericiler, uygulamacılar ve ormancılık sektörünün geniş ölçüde benimsediği, ormancılık yönetiminin bir parçası olan ağaçlandırma çalışmaları henüz hayata geçirilememiştir. Bu kapsamda, ABD'nin güney eyaletlerinde yapılan bir y1llık inceleme ve gözlemlerin değerlendirilmesi 1şığında, Türkiye'deki ağaçlandırmalar için aşağıdaki önerilerin yapılması ve bazılarının daha önceki yayınlarda (Şıklar ve Öztürk, 2009; Şıklar ve ark., 2017; TOD, 2019) geçmesinden dolayı tekrar edilmesi uygun görülmüştür.

a.Amenajman planlama yönteminden yararlanılarak, ağaçlandırmalara özel bir örnekleneme yapılmalı ve Türkiye'de bugüne kadar yapılmış 2.5 milyon ha ağaçlandırmanın durumu ortaya konulmalidir.

b.Türkiye'de ağaçlandırmaya ayrılacak/ayrılmış (tahsis) alanlar belirlenmeli ve sinırları harita üzerinde çizilmelidir. Sınırlar belirlendikten sonra çok sıklıkla olmamak kaydıyla bilimsel veriler 1 şığında düzeltmeler (revizyon) yapılabilir.

c.Türkiye'de k1sa, orta ve uzun vadeli olarak orman ürünleri talepleri ortaya konulmalıdır. Ortaya çıkan taleplere göre ağaçlandırmaların amacı belirlenmeli ve bu amaca göre planlanmalidir.

d.Ağaçlandırma çalışmalarının, her paydaşın kabul edebileceği bilimsel bir temele oturtulması için ağaçlandırmaların başlangıcında ve ilerleyen aşmalarında ortaya çıkan sorunlara yönelik, Türkiye'ye özgü araştırmalar yapılmalıdır.

e.Ağaçlandırmalarda planlama (etüt ve proje) çok iyi yapılmalı, toprak eşleştirme, sslah edilmiş fidanların sağlanması vb. önemli aşamalar tamamlanmadan uygulamaya geçilmemelidir. Ayrıca ağaçlandırmaların uzun dönemli yatırımlar olduğu dikkate alınarak, Etüt-proje birimlerinde toprak ve ekoloji uzmanları işlendirilmelidir.

f.Dünyada ağaç ıslahının, ağaçlandırmalarda birim alandan üretimi artırmada giderek etkisi artan bir bileşen olduğu kabul edilmiştir. Özellikle kızılçam için genetik değeri daha yüksek (2., 3., ...n. generasyon) materyallerin ağaçlandırmalarda kullanılmasını sağlayacak yapay dölleme çalışmaları başlatılmalıdır.

g.Ağaçlandırma için yetişmiş ve deneyimli personel (uygulamacilar) elde tutulmalı, yenileri yetiştirilmeli ve ağaçlandırma çalışmalarındaki etkinlikleri (araç gereç, eleman) desteklenmelidir. Diğer yandan karar vericiler ağaçlandırma konusunda çok sık karar değiştirmemeli ve ağaçlandırma sürdürülebilir bir kurum (OGM) politikası haline getirilmelidir. Ormanc1lık 
sektörü (özellikle odun hammaddesini girdi olarak kullanan şirketler) uluslararası düzeyde ekonomik dalgalanmaları da göz önüne alarak, kısa dönemli çabalar yerine, ağaçlandırma için kendilerinin de çıkarına olabilecek uzun dönemli katkılarda bulunmalıdırlar. ABD'nin güney eyaletlerinde, şirketler (kooperatif üyeleri), araştırmalar ve ağaç 1slahının geliştirilmesi için üniversitelere çok büyük kaynaklar aktarmaktadır. Bunun yanında kendilerine ait tohum bahçeleri ve fidanlıklar kurmakta ve ağaçlandırmalarını kendi arazilerinde, kendi olanakları ile yapmaktadirlar.

\section{Teşekkür}

Bu çalışma, TÜBİTAK 1059B191800583 kodlu Doktora Sonrası Araştırma Burs Programı kapsaminda (2019-2020/ ABD North Carolina State Üniversitesi) üretilmiştir. Ayrıca, Orman Mühendisleri, Sadi Şıklar, Rumi Sabuncu, Mehmet Emin Çetin ve Cemal Gültekin'in yanında Prof. Dr. Fikret Isik ve Doç. Dr. Fatih Temel eleştiri ve önerileri ile önemli katkılar sağlamışlardır. Katkıları için çok teşekkürler.

\section{Kaynaklar}

Alan, M. 2012. Türkiye de kızılçam 1slahının dünü bugünü ve geleceği. Kurulusunun 60. Y1lında Ormancılık Araştırma Enstitüleri: Dünü, Bugünü ve Geleceği Sempozyumu, 212-220

Alan, M. 2020. Silviculture and tree breeding for planted forests. Eurasian Journal of Forest Science, (8(1): 74-83)

Alan, M., Ezen, T., Öztürk, H., Şıklar, S., Sabuncu, R. Derilgen, S. I., Çalıkoğlu, M., Polat, O. 2012. Akdeniz Bölgesi Alçak Islah Zonu'nda (0-400 m) kızılçam (Pinus brutia Ten.) döl denemeleri (12. yaş sonuçları). Orman Ağaçları ve Tohumları Islah Araştırma Enstitüsü Müdürlüğü, Teknik Bülten No: 29, Ankara

Boydak, M., Çalışkan, S. 2014. Ağaçlandırma. OGEMVAK, 712s, İstanbul

Carle, J.B., Holmgren, L.P.B. 2009. Wood from planted forests: global outlook to 2030. In: Evans J. (Ed.), PLANTED FORESTS Uses, Impacts and Sustainability (Vols. 1-213, pp. 47-60). Rome, Italy: CAB International and FAO

Erkan, N. 1996. Kızılçamda (Pinus brutia Ten.) mescere gelişiminin simulasyonu. Güneydoğu Anadolu Ormancılık Araştırma Enstitüsü, Teknik Bülten No: 1, 148 s., Elâzığ

Erkan, N., Ok, K., Parlak, S. 2020. ENAT Karacabey endüstriyel ağaçlandırma yatırımında hasılat ve iç karl1lık analizi. Ormancılık Araştırma Dergisi, (7 (1), 62-75) DOIhttps://doi.org/10.17568/ogmoad.616270

Evans, J. 2009. The history of tree planting and planted forests. In: Evans J. (Ed.), PLANTED FORESTS Uses, Impacts and Sustainability (Vol. 213, pp. 5-22). Rome, Italy: CABI International and FAO.

FAO. 2020. Global Forest Resources Assessment 2020: Main report. Rome. https://doi.org/10.4060/ca9825en

Fox, T.R., Jokela, E.J., Allen, H.L. 2004. The evolution of pine plantation silviculture in the Southern United States. In: Rausher HM, Kurt J(Ed.), Southern Forest Science: Past, Present and Future (Vols. 1-394, pp. 63-82). United States Department of Agriculture Forest Service, Southern Research Station.

Fox, T.R., Jokela, E.J., Allen, H.L. 2007. The development of pine plantation silviculture in the Southern United States. Journal of Forestry, (105(7), 337-347). https://doi.org/10.1093/jof/105.7.337

Huggett, R., Wear, D.N., Ruhong, L., Coulston, J., Liu, S. 2013. Forecasts of forest conditions. Chapter 5. P. 542 in The Southern Forest futures project: Technical report. USDA Forest Service Gen. Tech. Rep. SRS-178, Wear, D.N., and J.G. Greis (eds.). Southern Research Station, Asheville,NC.

Isik, F., McKeand, S. 2019. Fourth cycle breeding and testing strategy for Pinus taeda in the NC State University Cooperative Tree Improvement Program. Tree Genetics \& Genomes, (15(5)-70: 1-12). https://doi. org/10.1007/s11295-019-1377-y

Işı1k, K. 1991. Amerika Birleşik Devletleri'nin Güneydoğu Eyaletlerinde, orman ağacı 1slahı konusundaki uygulamalar ve gelişmeler. Orman Mühendisliği Dergisi, 28(3): 8·14· 1991

Koski, V., Antola, J., 1994. Turkish National Tree Breeding and Seed Production Program for Turkey (19942003), Volume 2: Technical Instructions. Prepared in Cooperation with ENSO Forest Development Inc and Forest Tree Seeds and Tree Breeding Institute, Ankara.

McKeand, S. 2015. The success of tree breeding in the Southern US. BioResources, (10: 1-2)

McKeand, S. 2017. New challenges for seed orchard management of loblolly pine in the Southern US. IUFRO Seed Orchard Conference, p18, September 4-6, 2017 Bålsta, Sweden

McKeand, S. 2019. The evolution of a seedling market for genetically improved Loblolly pine in the Southern United States. Journal of Forestry, (117(3): 293-301). https://doi.org/10.1093/jofore/fvz006

McKeand, S., Gerwig, D.M., Cumbie, W.P., Jett, J.B. 2008. Seed orchard management strategies for deployment of intensively selected Loblolly Pine families in the Southern US. In: Lindgren D (ed). Treebbredex \& SLU, Sweden, pp 177-182

McKeand, S., Mullin, T., Byram, T., White, T. 2003. 
Deployment of genetically improved Loblolly and Slash Pines in the South. Journal of Forestry, (101(3): 32-37). https://doi.org/10.1093/jof/101.3.32

Mead, D.J. 2013. Sustainable management of Pinus radiata plantations. Food and Agriculture Organization of the United nations (FAO).

NCSU TIP. 2020. North Carolina State University Tree Improvement Program web sitesi, http://treeimprovement.org/sites/default/files/20_AR_final_web.pdf (Erişim tarihi: 18.08 .2020 )

OATIAM. 2020. Orman Ağaçları ve Tohumları Islah Araștırma Enstitüsü Müdürlüğü web sitesi https://ortohum.ogm.gov.tr/SitePages/OGM/OGMDefault.aspx (Erişim tarihi 18.08.2020)

OGM. 2004. Türkiye Ulusal Ormancıllk Programı. https://www.ogm.gov.tr/ekutuphane/Dokumanlar/ Ulusal_Ormancilik_Programi_2004_2023.pdf (Erişim tarihi: 18.08 .2020 )

OGM. 2013. Endüstriyel Ağaçlandırma Çalışmaları Eylem Plan1 (2013-2023).

OGM. 2018. Orman Gene Müdürlüğü Stratejik Plan (2019-2023) https://www.ogm.gov.tr/ekutuphane/StratejikPlan/Orman $\% 20 \mathrm{Genel} \% 20 \mathrm{M} \% \mathrm{C} 3 \% \mathrm{BCd} \% \mathrm{C} 3 \%$ $\mathrm{BCrl} \% \mathrm{C} 3 \% \mathrm{BC} \% \mathrm{C} 4 \% 9 \mathrm{~F} \% \mathrm{C} 3 \% \mathrm{BC} \% 20$ Stratejik $\% 20$ Plan\%20(2019-2023).pdf (Erişim tarihi 18.08.2020)

OGM. 2020. Orman Genel Müdürlüğü web sitesi (https://www.ogm.gov.tr/ekutuphane/Sayfalar/Istatistikler. aspx), (Erişim tarihi: 18.08.2020)

Onyekwelu, J.C., Stimm, B., Evans, J. 2011. Review plantation forestry. In Silviculture in the Tropics (pp. 399-454). Springer, Berlin, Heidelberg.

ÖİK. 2014. Özel İhtisas Komisyon Raporu: sürdürülebilir orman yönetimi (2014-2018). Kalkınma Bakanlığ1 Yayın no: KB: 2872 - ÖİK: 722

Özel, H.B., Daşdemir, İ., Üzgün, S. 2017. Balıkesir-Manyas yöresi Kızılçam (Pinus brutia Ten.) ağaçlandırmalarının teknik ve ekonomik analizi. 2023'e Doğru 4. Doğa ve Ormancilik Sempozyumu, 43-55. ISBN: 978-605- 01-
1108-8. Antalya.

Öztürk, H., Șıklar, S. 2000. Türkiye Milli Ağaç Islahı ve Tohum Üretim Programı (özellikleri ve gerçekleştirilen çalışmalar). Orman Ağaçları ve Tohumları Islah Araştırma Müdürlü̆̆̈̈ Dergisi, (1: 1-41)

Payn, T., Carnus, J.M., Freer-Smith, P., Kimberley, M., Kollert, W., Liu, S., Orazio, C., Rodriguez, L., Silva, L.N., Wingfield, M.J. 2015. Changes in planted forests and future global implications. Forest Ecology and Management, (352: 57-67). https://doi.org/10.1016/j.foreco.2015.06.021

Ruotsalainen, S. 2014. Increased forest production through forest tree breeding. Scandinavian Journal of Forest Research, (29(4): 333-344). https://doi.org/10.1080/ 02827581.2014 .926100

Şıklar, S., Öztürk, H. 2009. Türkiye'de odun hammaddesi üretiminin artırılması açısından Kızılçam ( $P$. brutia Ten.) endüstriyel plantasyon ormancilığı. Orman Mühendisliği Dergisi, (Say1: 7-8-9: 26-29)

Şıklar, S., Öztürk, H., Alan, M. 2017. Kızılçam (Pinus brutia Ten.) genetik 1slah çalışmalarının endüstriyel ağaçlandırmaların verimliliğine etkisi. 2023'e Dogru 4. Doga ve Ormanc1l1k Sempozyumu, 2017, 71-82

Stanturf, J.A., Kellison, R.C., Broerman, F.S., Jones, S.B. 2003. Productivity of Southern pine plantations: where are we and how did we get here? Journal of Forestry, (101(3): 26-31). https://doi.org/10.1093/jof/101.3.26

TOD. 2019. Orman Genel Müdürlüğünce uygulanmakta olan "Endüstriyel Ağaçlandırma Çalışmaları Eylem Planı" üzerine değerlendirmeler ve öneriler. Türkiye Ormancılar Derneği, https://www.ormancilardernegi.org/ dosyalar/files/Endustriyel_Agaclandirma_Raporu.pdf (Erişim tarihi 18.08.2020)

Troxler, S. 2017. North Carolina Forest Service 2017- Biennial Report. North Carolina.

Usta, H. 1991. Kızılçam (Pinus brutia Ten.) ağaçlandırmalarında hasılat araştırmaları. Ormancılık Araștırma Enstitüsü, Teknik Bülten No: 219, 138 s., Ankara. 